\title{
Manifiesto universal Poetas del Mundo
}

Luis Arias Manzo

Secretario General, Chile

$\mathbf{P}$ oetas del Mundo, ha llegado el instante en que debemos unir las fuerzas para defender la continuidad de la vida: Somos los Guerreros de la Paz y los Mensajeros de una nueva etapa en la Humanidad. Somos los Poetas de la Luz, y la Luz es el vehículo que nos conduce a la convocatoria a la que por ningún motivo debemos dejar de asistir. Vivimos actualmente el proceso de muerte de una etapa degenerada y el nacimiento de una NUEVA ERA en que el poeta tiene un rol determinante que jugar.

La humanidad vive tiempos decisivos para su sobrevivencia: sigue con dirección hacia el precipicio que la conduce a la extinción o cambia de timón fijando trayectoria hacia la superación colectiva que le asegure larga subsistencia.

Desde los tiempos más remotos que el hombre recuerde, la existencia humana se ha visto confrontada a coexistir con los medios ambientales los que le aseguraron, y le siguen asegurando, la posibilidad de vivir. Pero al mismo tiempo y paradójicamente, el hombre en su afán de ser más, de crecer y crecer, ha ido deteriorando el planeta hasta llevarlo a límites que ponen en peligro la posibilidad de seguir existiendo como especie. Si el hombre no cambia de rumbo, ¡Y AHORA!, las próximas generaciones tendrán sólidas razones para odiarnos.

Por otro lado, en este mismo contexto de querer ser siempre MÁS, no sólo se usan los medios materiales del planeta para crecer y subsistir, sino que también los medios humanos, arrastrándonos a la despiadada y criminal competencia entre los hombres a tal punto que hoy nos estamos matando entre nosotros mismos para existir, para crecer o simplemente para decir: SOY, esto o lo otro, pero ¡SOY! O soy más que tú...

Así como deterioramos el planeta constantemente con el uso abusivo de los recursos naturales y humanos, así se construyen armas de destrucción a gran escala, capaces de destruir toda la humanidad en pocas horas, y la supremacía del poder se concentra siempre en las mismas manos, en lo que hoy conocemos como Imperio [s]. 
Pero no todo es negativo, porque el caos moral, el caos ético, el caos político [guerras infames], el caos económico [cosas absurdas] no son sino manifestaciones del PARTO DE LA HISTORIA como cuando una mujer da a luz un niño; muere una etapa y surge otra de su seno.

1. Frente a este afán de dominio absoluto que nos podría llevar inevitablemente a la autodestrucción y ante tanta barbaridad, y a la luz de los nuevos tiempos que se anuncian, los Poetas del Mundo emprendemos el camino de la protesta, por un lado, y de la construcción de un nuevo amanecer, por otro, que conduce a la liberación definitiva del hombre.

2. Los Poetas del Mundo, no todos, sólo los Poetas del Mundo, porque no todos los poetas del mundo estamos dispuestos a decir: no soy, SOMOS. Los que estamos dispuestos a abandonar el EGO que nos está matando y somos capaces de mirarnos en IGUALDAD, iniciamos la cabalgata colectiva a través del mundo y ponemos el arte de la poesía al servicio de la humanidad.

3. Ser poeta no significa sólo escribir bella poesía, sino que VIVIRLA, y vivirla no significa, sólo sentirla, sino que practicarla, y practicarla es una cosa de todos los días, de siempre mientras tenemos cabeza para pensar y corazón para sentir.

4. Ser Poeta del Mundo es algo más difícil todavía, ser Poeta del Mundo es asumir este manifiesto en su parte esencial; es asumir la defensa de la vida, del amor, de la diversidad, de la libertad y ser capaz de decir: doy mi vida por la VIDA, aunque amo mi vida. Por eso es que decimos BASTA de estupideces, BASTA de EGOS que no contribuyen al crecimiento colectivo, ni personal, y ponemos el arte de la poesía al servicio de la existencia humana.

5. Ser Poeta del Mundo es ser un guerrero, o una guerrera, que cabalga por las llanuras de la existencia humana, como lo hizo desde la noche de los tiempos, en busca de la perfección y del crecimiento lícito de la vida, mientras se vive con los ropajes y las condiciones que tenemos para hacerlo. Es por eso que no seremos pasivos ante los crímenes que se cometen día a día en nombre de la libertad, levantaremos nuestra voz como un rayo de luz y haremos temblar al cobarde, porque la palabra la convertiremos en la mejor arma que el asesino haya conocido a lo largo y ancho de la historia.

6. Reconocemos el valioso aporte de los poetas del mundo al crecimiento de la humanidad a través de los siglos. Aquellos que dejaron su nombre estampado en los centenarios libros de la historia universal y en la memoria colectiva de los hombres, y también reconocemos el aporte de los anónimos poetas que pasaron por la Tierra cumpliendo con misiones legendarias a través de los tiempos. Creemos en el valor que significaron esas majestuosas contribuciones para sus tiempos, incluso para hoy, pero estamos en el umbral de una nueva etapa que queremos enredar con el pasado para mejor mirar el presente y el futuro.

Los Poetas del Mundo de este siglo estamos llamados a ser creativos para con imaginación encontrar las respuestas y 
explicaciones que HOY la humanidad reclama a gritos ante el evidente descalabro que estamos viviendo.

7. Los Poetas del Mundo nos declaramos todos iguales, los consagrados y los menos conocidos, los famosos y los anónimos, los ricos y los pobres, los blancos y los negros, los mestizos y los amarillos, siempre y cuando se sitúen a este lado de la vida; empuñando las mismas espadas para combatir lo que mata la vida, luchando codo a codo tras la misma barricada para defender la JUSTICIA [única para todos], la IGUALDAD [efectiva entre todos los habitantes de la Tierra], la LIBERTAD [la verdad, no la artificial] y el DERECHO de los pueblos a existir y vivir en paz.

8. Los Poetas del Mundo declararán cualquier espacio donde les toque estar o ser, como la arena propia para combatir el mal, ya sea en los grandes y fríos palacios del poder o en la mísera caverna de la urbe, en el césped donde labora el hombre de la tierra o en el fondo mismo de la mina donde escupe sangre el minero, pero el poeta no dejará de visitar ningún barrio para llevar la palabra, como si ésta fuese lluvia que cae sobre la tierra, haciendo ver un espectáculo de gracia, como si fueran flores para los ojos de la humanidad. El poeta será la luz que guía al guerrero como si fueran dunas en la oscuridad de la noche.

9. Los Poetas del Mundo nos declaramos pacifistas, pero ni cobardes ni pasivos; antibelicistas, pero de ninguna manera ingenuos. Sentimentalistas por naturaleza porque la expresión artística, la tinta de la escritura, es la sangre de nuestras almas. Vivimos atrapados por la embriaguez del encanto artístico, hasta el vértigo doloroso de la creación. Pero esta creación tendrá siempre un objetivo determinado: PERFECCIONAR LA VIDA, la nuestra [la individual], la de todos [en colectividad]. Somos pacifistas en busca de la paz universal, pero LA PAZ no viene porque sí, hay que ganársela, luchar por ella. Por ello somos Guerreros. Y la PAZ no será si no hay JUSTICIA. La PAZ sólo será cuando reine primero la justicia, porque ella sólo puede serla si es consecuencia, fruto de la justicia. Si no será lo que es ahora en el reinado de los Imperios: PAZ DE CEMENTERIO.

10. Para ser Poeta del Mundo hay que estar dispuesto a perfeccionarse siempre, a crecer en la diversidad y aceptar la pluralidad como aceptamos la complejidad de la existencia. En el batallón de los Poetas del Mundo habrá espacio siempre para luchar, ya sean creyentes o no creyentes, ateos o religiosos, justos o equivocados, pero de este lado de la VIDA; heterosexuales, bisexuales u homosexuales, pero amantes del AMOR noble; guerreros de antaño o combatientes modernos, pero siempre militantes del BIEN. La gran cadena humana que una al mundo, eslabón, estará conformada por poetas repartidores de esperanzas y sonrisas en esta lucha que dura desde el alba de los tiempos.

11. El hombre buscará en un tercero sus culpas, nuestro reto es que cada quien se asuma en su esencia, bajo su propio espíritu, sin tener que acudir al tercero para acallar sus errores y derrotas. Nuestra esperanza es alzarnos por medio de la palabra, encender el verbo en los corazones de cada uno, el verso de las montañas, la 
noche sigilosa del alma, el envoltorio cuidadoso del vientre de la natura, ser vidente en la mañana, para que cada quien alce su alma con amor, con palabras. La poesía es del mundo y nos debemos a ella.

\section{Poeta del Mundo}

¡Únete a esta batalla por la existencia humana!

¡Conviértete en el eslabón necesario para que continúe la VIDA!

www.poetasdelmundo.com

-E-mail: info@poetasdekmundo.com 